\title{
Female Psychological Adjustment Following an Acute Coronary Syndrome
}

\section{Adaptação Psicológica nas Mulheres Após Síndrome Coronária Aguda}

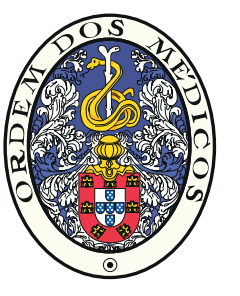

Joana PRATA ${ }^{1}$, Amadeu Quelhas MARTINS 2,3 , Sónia RAMOS ${ }^{1}$, Francisco ROCHA-GONÇALVES ${ }^{1}$, Rui COELHO
Acta Med Port 2017 May;30(5):373-380 - https://doi.org/10.20344/amp.7871

\section{ABSTRACT}

Introduction: The outcomes of cardiovascular disease are consistently worse among women, regardless of age or disease severity. Such trend might arise from psychosocial factors, which should be examined in this population.

Objective: To evaluate the influence of type-D personality on anxiety and depression symptoms reported by female patients after a first acute coronary syndrome.

Material and Methods: As part of a larger study, 34 female patients with a first acute coronary syndrome were compared with 43 controls on psychosocial measures (Hospital Anxiety and Depression Scale; type-D personality, DS - 14).

Results: Hypertension $(p<0.001)$, diabetes $(p<0.05)$, dyslipidemia $(p<0.05)$, type-D personality $(p=0.001)$ and anxiety $(p<0.001)$ were more prevalent among patients. Exercise $(p<0.05)$ and antidepressant use $(p<0.05)$ were more common among controls. Logistic regression analysis confirmed that higher prevalence of hypertension $(p<0.05)$, dyslipidemia $(p<0.05)$, type-D personality $(p<$ $0.05)$, anxiety $(p<0.05)$ and less antidepressant use $(p<0.05)$, were independently associated with acute coronary syndrome. Type-D personality was associated with higher Hospital Anxiety and Depression Scale scores in controls (anxiety: $p=0.001$; depression: $p<$ 0.001 ) but not in patients.

Discussion: High anxiety after an acute coronary syndrome might reflect a short-term adaptive response, albeit worsening the disease long-term prognosis. The lack of differences in some group comparisons (patients versus controls for depression scores; type-D 'positive' versus type-D 'negative' for anxiety and depression scores within patients) is discussed.

Conclusion: Type-D personality, high anxiety, hypertension and dyslipidemia seem to cluster among female acute coronary syndrome patients. Nevertheless, type-D personality itself was not associated with higher anxiety and depressive scores during the post-acute period.

Keywords: Acute Coronary Syndrome/psychology; Adaptation, Psychological; Anxiety Disorders; Depressive Disorder; Female

\section{RESUMO}

Introdução: As consequências da doença cardiovascular são consistentemente piores em mulheres, independentemente da idade ou gravidade da doença. Esta tendência pode resultar de factores psicossociais que devem ser examinados nesta população.

Objectivo: Avaliar a influência da personalidade tipo-D nos sintomas de ansiedade e depressão reportados por mulheres após uma primeira síndrome coronária aguda.

Material e Métodos: Como parte de um estudo mais alargado, compararam-se 34 mulheres com uma primeira síndrome coronária aguda com 43 controlos em medidas psicossociais (Hospital Anxiety and Depression Scale; Personalidade tipo-D, escala DS - 14).

Resultados: Hipertensão $(p<0,001)$, diabetes $(p<0,05)$, dislipidemia $(p<0,05)$, personalidade tipo-D $(p=0,001)$ e ansiedade $(p<$ $0,001)$ foram mais prevalentes nas doentes. A prática de exercício $(p<0,05)$ e a toma de antidepressivos $(p<0,05)$ foram mais comuns entre controlos. A análise de regressão logística confirmou que uma maior prevalência de hipertensão $(p<0,05)$, dislipidemia $(p<$ $0,05)$, personalidade tipo-D $(p<0,05)$, ansiedade $(p<0,05)$ e uma menor utilização de antidepressivos $(p<0,05)$, estavam independentemente associados à síndrome coronária aguda. A personalidade tipo-D associou-se a maiores pontuações Hospital Anxiety and Depression Scale nos controlos (ansiedade: $p=0,001$; depressão: $p<0,001$ ), mas não nas doentes.

Discussão: Ansiedade elevada após uma síndroma coronária aguda pode traduzir uma resposta adaptativa a curto-prazo, embora agrave o prognóstico da doença a longo-prazo. A ausência de diferenças em algumas comparações (doentes versus controlos para pontuações de depressão; tipo-D 'positivos' versus tipo-D 'negativos' para pontuações de ansiedade e depressão entre doentes) é discutida.

Conclusão: A personalidade tipo-D, ansiedade, hipertensão e dislipidemia parecem associar-se nas doentes com síndroma coronária aguda. Apesar disso, a personalidade tipo-D não se associou a maiores pontuações de ansiedade e depressão no período pós-agudo. Palavras-chave: Perturbação Depressiva; Perturbações de Ansiedade; Mulheres; Síndrome Coronária Aguda/psicologia

\section{INTRODUCTION}

Approximately $55 \%$ of all female deaths in Europe are caused by cardiovascular disease (CVD), in particular coronary artery disease and stroke, ${ }^{1}$ more than one in five women die because of ischemic heart disease (IHD) and the disability burden is expected to rise concomitantly given

the longer life expectancy of women. ${ }^{2}$

In recent years, gender differences in prevalence rates, symptom profiles and even medical outcomes have accumulated. ${ }^{1-4}$ Women with IHD have worse outcomes than men regardless of age $^{3}$ and female pathophysiology

1. Cardiovascular Research Unit. Faculty of Medicine. University of Porto. Porto. Portugal.

2. Department of Psychology. Universidade Europeia. Laureate International Universities. Lisbon. Portugal.

3. Microenvironments for New Therapies Group. Instituto de Investigação e Inovação em Saúde. University of Porto. Porto. Portugal.

4. Department of Clinical Neurosciences and Mental Health. Faculty of Medicine. University of Porto. Porto. Portugal.

$\triangle$ Autor correspondente: Joana Prata. joanappr@gmail.com

Recebido: 20 de maio de 2016 - Aceite: 06 de fevereiro de 2017 | Copyright @ Ordem dos Médicos 2017 
of myocardial ischemia, biochemical and neuro-hormonal factors might combine to place women at a disadvantage. ${ }^{3}$ Further, classical biomedical risk factors can have a different relative weight depending on gender ${ }^{4}$ and psychosocial factors reliably implicated in the risk and expression of CVD, also present important gender differences. ${ }^{5-7}$

Depressive symptoms have been consistently associated with worse prognosis among CVD patients and self-reported depressive symptoms are independent prognostic factors of cardiac mortality even in the absence of a clinical diagnosis of depression. ${ }^{8}$ As in the general population, female CVD patients are twice as likely to experience depression. ${ }^{9}$ Depression is also an established risk factor for CVD in the community, increasing both cardiac morbidity and cardiac mortality. ${ }^{10-12}$ Similarly, anxiety has also been identified as a risk factor for worse prognosis in cardiac patients ${ }^{13,14}$ and is also an independent risk factor for CVD in community samples, ${ }^{11,14,15}$ with recent evidence pointing to $20 \%-30 \%$ increased risk for first acute myocardial infarction (AMI). ${ }^{11}$

Stable personality traits relating to distress have also been implicated in CVD. ${ }^{16}$ Type-D (distressed) personality comprises traits of negative affectivity and social inhibition and has been associated with a wide range of adverse health outcomes. ${ }^{17}$ Prevalence rates range from $25 \%$ to $28 \%$ among CVD patients ${ }^{17}$ and from $10 \%$ to $40 \%$ in the general population, ${ }^{17-21}$ although studies evaluating type-D personality in women are lacking. Among CVD patients, type-D personality has been associated with an increased risk of both cardiac events and worse outcome. ${ }^{22,23}$ In community studies, type-D participants experience high levels of mental distress and poor physical health status. ${ }^{19}$ However, it is unknown whether type-D personality influences emotional adjustment responses following a serious cardiac event.

\section{MATERIAL AND METHODS \\ Participants}

As part of a larger longitudinal study examining the impact of psychosocial factors in cardiac patients' prognosis, 34 female patients consecutively admitted with a first episode of ACS to the coronary unit of a general hospital in Porto, Portugal, were recruited. In parallel, 43 female controls matched by age were recruited at primary health provision contexts and general practices located in the same Health Administration Region. The study protocol was approved by the Ethics Review Board and written informed consent was obtained from all study participants.

Women in the ACS group were evaluated during hospitalization (first week after the acute event). Patients were identified as eligible by the attending cardiologist (according to the 'Third Universal Definition of Myocardiall nfarction - Expert Consensus Document' by the European Society of Cardiology) ${ }^{24}$ and were assessed for sociodemographic, behavioral, clinical, psychosocial variables and cardiovascular risk factors. Clinical variables associated with the ACS were obtained from patients' medical records and are shown in Table 1. Cardiac patients were excluded if they were unable to fill self-evaluation questionnaires or had cognitive impairment (a score below or equal to 24 in the Mini-Mental State Examination). ${ }^{25}$ Exclusion criteria for female controls included cardiovascular disease, either documented in clinical records or self-reported, and cognitive impairment (a score below or equal to 24 in the Mini-Mental State Examination). ${ }^{25}$ Characteristics of the control group regarding socio-demographic, behavioral, psychosocial variables and cardiovascular risk factors are also shown in Table 1.

\section{Instruments}

The Hospital Anxiety and Depression Scale (HADS) is a self-evaluation questionnaire which comprises two subscales, one measuring depression (HADS-D) and the other measuring anxiety (HADS-A) ${ }^{26,27}$ The HADS is a presentstate instrument, that is, it emphasizes on the condition within the last week. The HADS has been validated for the Portuguese population in different patient groups (including patients with coronary heart disease ${ }^{28}$ and is also recommended for use in community settings and primary health care. The HADS consists of two subscales, one measuring anxiety and the other depressive symptoms which are scored separately. Each subscale consists of seven items, answered by the patient on a 4 - point scale $(0$ to 3 ) so that the scores can vary from $0-21$. According to the HADS manual, a HADS cutoff score of greater than 7 in any of the subscales indicates the presence of symptoms, i.e. HAD-D $\geq 8$ indicates depressive symptoms ${ }^{27}$ and this cutoff was also used in the present study. Also, the HADS has been considered more consistent in evaluating depression in ACS patients for containing less somatic symptoms that could be more readily influenced by health status. ${ }^{29}$

A Portuguese version of the type-D scale-14 (DS-14) has been validated for the Portuguese population and was used in this study to measure type-D personality. ${ }^{30}$ The DS14 consists of 14 items, 7 assessing negative affectivity (NA) and the other 7 assessing social inhibition ( $\mathrm{SI}$ ). Each item is rated on a five-point scale, ranging from 0 to 4 . A score of at least 10 in both sub-scale identifies individuals as having type-D (or distressed) personality. ${ }^{17}$ In this study we used a cut-off of 10 for both subscales which is considered to be the most reliable for use in clinical samples, including patients with cardiovascular disease and in the general population. According to Emons et al, ${ }^{31}$ in a study using item response theory, all items had highest measurement precision around the cut-off measurements and were fairly comparable across the general population and clinical populations.

\section{Data analysis}

In this study, we started by comparing a set of cardiovascular risk factors and psychosocial measures between the group of first ACS episode female patients and the group of age-matched female controls. Next, we sought to identify predictors of ACS among the patients group to examine whether any psychosocial measure could contribute independently to a higher risk of ACS. 
Table 1 - Baseline characteristics of participants

\begin{tabular}{|c|c|c|c|}
\hline Variables & Control group $(n=43)$ & ACS group $(n=34)$ & $p$ \\
\hline \multicolumn{4}{|l|}{ Demographic characteristics } \\
\hline Age $(M \pm S D)$ & $64.3 \pm 8.2$ & $65.7 \pm 9.5$ & 0.49 \\
\hline Education $(\mathrm{M} \pm \mathrm{SD})$ & $8.2 \pm 3.9$ & $5.4 \pm 4.1$ & 0.003 \\
\hline Living alone (\%) & 16.3 & 14.7 & 0.850 \\
\hline \multicolumn{4}{|l|}{ Lifestyle characteristics } \\
\hline Smoking (\%) & 23.3 & 14.7 & 0.347 \\
\hline Alcohol consumption (\%) & 23.3 & 38.2 & 0.154 \\
\hline Exercise (\%) & 58.1 & 26.5 & 0.005 \\
\hline \multicolumn{4}{|l|}{ Clinical characteristics } \\
\hline $\mathrm{BMI}(\mathrm{M} \pm \mathrm{SD})$ & $25.7(4.4)$ & $26.8(4.6)$ & 0.278 \\
\hline Hypertension (\%) & 25.6 & 76.5 & $<0.001$ \\
\hline Diabetes (\%) & 4.7 & 20.6 & 0.031 \\
\hline Dyslipidemia (\%) & 34.9 & 70.6 & 0.002 \\
\hline \multicolumn{4}{|l|}{ ACS characteristics } \\
\hline \multicolumn{4}{|l|}{ Diagnosis } \\
\hline NSTEMI / unstable angina & NA & 64.7 & \\
\hline STEMI & NA & & \\
\hline Anterior & & 5.9 & \\
\hline Inferior & & 14.7 & \\
\hline Lateral & & 8.8 & \\
\hline Undetermined & & 5.9 & \\
\hline LVEF & NA & & \\
\hline$>55 \%$ & & 76.4 & \\
\hline $40 \%-55 \%$ & & 11.8 & \\
\hline $30 \%-40 \%$ & & 11.8 & \\
\hline CABG (\%) & NA & 8.8 & \\
\hline Troponin $(\mathrm{M} \pm \mathrm{SD})$ & NA & $20.5 \pm 26.1$ & \\
\hline Systolic BP (M \pm SD) & NA & $141 \pm 27.5$ & \\
\hline Diastolic BP (M $\pm \mathrm{SD})$ & NA & $79.8 \pm 17.2$ & \\
\hline
\end{tabular}

M \pm SD: Mean \pm Standard deviation; BMI: Body Mass Index; ACS: Acute coronary syndrome; NSTEMI: Non-ST elevation myocardial fnfarction; STEMI: ST elevation myocardial infarction; LVEF: Left ventricular ejection fraction; CABG: Coronary artery bypass graft; BP: Blood pressure; NA: Non applicable

Finally, we assessed whether a positive status for type D personality would be associated with worse psychological adjustment, in terms of anxiety and depression symptoms, and whether this link would be more evident among patients.

All analyses were carried out with the Statistical Package for the Social Sciences - SPSS (version 19). Exploratory analyses examined the normality of the distribution of data points for each group (patients/controls) with the ShapiroWilk test. No transformation was deemed necessary for the sampled data. Univariate analyses compared demographic, behavioral, clinical, and psychometric variables between the control group and the ACS group. Differences between proportions were examined with Chi-squared tests whereas mean comparisons were conducted with Student $t$ tests. The homogeneity of variances was inspected through the Levene test, and the appropriate t values adjusted for the corrected degrees of freedom were considered in those instances of significantly uneven variances. A multiple logistic regression analysis (backward LR method) was conducted to quantify the independent associations of previously identified correlates with cardiovascular disease. The assumption of non-collinearity in the logistic regression model was studied through an exploratory analysis of nonparametric Spearman's bivariate correlation coefficients, which were initially computed between the categorical predictors. Spearman's $r$ ranged between -0.12 (use of antidepressants $x$ hypertension) and 0.57 (type-D personality $x$ anxiety), but most correlations lagged behind 0.30 . Therefore, the data matrix did not require any transformation. Adjusted odds ratios (OR) with 95\% confidence intervals were included in the model summary. A series of 2 group (ACS patients, controls) by personality status (type-D, non-type-D) ANOVAs were conducted on anxiety and depression scores (HADS-A; HADS-D). The assumption of homogeneity of variances for the ANOVAs was again inspected with the Levene test. No 
violation was detected for both dependent variables (anxiety scores: Levene's $F=0.248 ; p=0.621$, for the patients vs controls comparison within the non-type-D participants; Levene's $\mathrm{F}=0.002$; $p=0.964$, for the patients vs controls comparison within the type-D participants; depression scores: Levene's $F=0.027 ; p=0.869$, for the patients versus controls comparison within the non-type-D participants; Levene's $\mathrm{F}=0.004 ; p=0.952$, for the patients versus controls comparison within the type-D participants). Measures of effect size (Cohen's $d$, phi, odds ratio, and eta squared) were reported as required. A statistical significance level of $p<0.05$ was considered for all analyses.

\section{RESULTS}

\section{Univariate analyses}

Baseline characteristics were compared between control and ACS patients groups (see Table 1). Although groups were initially matched for age $(64.3 \pm 8.2$ vs $65.7 \pm 9.5 ; t=$ $-0.71 ; p=0.49 ; d=0.16)$, controls had significantly more years of education (8.2 \pm 3.9 vs $5.4 \pm 4.1 ; t=3.13$; $p<0.05$; $d=0.71$ ). As to lifestyle characteristics and CVD risk factors, ACS patients had significantly lower levels of exercise $\left(\chi^{2}=7.72 ; p=0.005 ; \varphi=-0.32\right)$, and more hypertension $\left(\chi^{2}=19.70 ; p<0.001 ; \varphi=0.51\right)$, diabetes $\left(\chi^{2}=4.67 ; p=\right.$ $0.031 ; \varphi=0.25)$ and dyslipidemia $\left(\chi^{2}=9.68 ; p=0.002\right.$; $\varphi=0.36)$. No significant differences were found between groups for smoking $\left(\chi^{2}=0.89 ; p=0.347 ; \varphi=-0.11\right)$, alcohol consumption $\left(\chi^{2}=2.03 ; p=0.154 ; \varphi=0.16\right)$, and BMI $(t=$ $-1.09 ; p=0.278 ; d=-0.25)$. The ACS group included 22 patients with a diagnosis of non-ST elevation myocardial infarction (NSTEMI)/ unstable angina and 12 patients with ST-elevation myocardial infarction (STEMI). From the total, $76.4 \%$ patients had a left ventricular ejection fraction (LVEF) in normal range and only $8.8 \%$ of patients were treated with coronary artery bypass graft surgery (CABG) (see Table 1). Considering psychosocial factors (Table 2), type-D personality $\left(\chi^{2}=11.78 ; p=0.001 ; \varphi=0.39\right)$ and anxiety symptoms (HADS-A, $\chi^{2}=27.12 ; p<0.001 ; \varphi=0.59$ ) were significantly more prevalent among ACS patients, whereas the groups did not differ on prevalence of either depressive symptoms (HADS-D, $\chi^{2}=1.93 ; p=0.165 ; \varphi=0.16$ ) or psychiatric referrals $\left(\chi^{2}=0.05 ; p=0.816 ; \varphi=-0.03\right)$. Curiously, antidepressant medication was significantly more common among the control group $\left(\chi^{2}=6.19 ; p=0.013 ; \varphi=0.28\right)$.

\section{Multiple logistic regression analysis}

A multiple logistic regression analysis (Nagelkerke $R^{2}=$ 0.576 ) for the independent correlates of female ACS (Table $3)$ revealed that hypertension $(p=0.014$; OR $=5.103)$, dyslipidemia $(p=0.049$; OR $=3.768)$, more anxiety (HADS-A) symptoms $(p=0.047$; OR $=4.315)$, type-D personality $(p=$ 0.045 ; OR $=4.605)$, and less antidepressant use $(p=0.008$; $\mathrm{OR}=0.045$ ) were all independently associated with ACS.

\section{Type-D personality impact on anxiety and depression symptoms}

A series of two group (ACS patients, controls) by two personality status (type-D, non-type-D) ANOVAs were conducted on HADS-A and HADS-D scores (Fig. 1). Overall, significant main effects on HADS-A were found for group $\left[F(1.73)=8.01 ; p<0.05 ; \eta^{2}=0.10\right]$ and personality status $\left[F(1.73)=11.90 ; p<0.001 ; \eta^{2}=0.14\right]$. Specifically, ACS patients $(\mathrm{M}=10.52 ; \mathrm{SE}=0.69)$ had significantly higher anxiety scores than controls $(M=5.42$; $S E=0.64)$. Similarly, type-D participants $(M=11.10$; $S E=0.80)$ scored significantly higher than non-type-D counterparts $(M=6.21$; $\mathrm{SE}=0.61$ ). Moreover, anxiety symptoms varied within each group, depending on the participants' personality status $\left[F(1.73)=3.47 ; p=0.07 ; \eta^{2}=0.05\right]$. Accordingly, type-D participants $(M=10.33, S E=1.57)$ had significantly higher scores $(t=-3.32, p<0.05)$ than non-type D participants (M $=4.62$; $\mathrm{SE}=0.63$ ) within the control group, whereas both

Table 2 - Univariate analyses of participants' psychometric outcome

\begin{tabular}{|c|c|c|c|}
\hline Variables & Control group $(n=43)$ & ACS group $(n=34)$ & $p$ \\
\hline DS - 14 Type D (NA $\geq 10$ and $S I \geq 10)(n, \%)$ & $6(14.0)$ & $17(50)$ & 0.001 \\
\hline HADS - A $\geq 8(n, \%)$ & $11(25.6)$ & $29(85.3)$ & $<0.001$ \\
\hline HADS - D $\geq 8(n, \%)$ & $8(18.6)$ & $11(32.4)$ & 0.165 \\
\hline Current antidepressant medication (n, \%) & $12(27.9)$ & $2(5.9)$ & 0.013 \\
\hline Psychiatric history (n, \%) & $15(38.9)$ & $11(32.4)$ & 0.816 \\
\hline
\end{tabular}

HADS-A: Hospital Anxiety and Depression Scale - Anxiety; HADS-D: Hospital Anxiety and Depression Scale - Depression; DS-14: Type-D Scale; NA: Negative affectivity; SI: Social inhibition; ACS: Acute coronary syndrome

Table 3 - Multiple logistic regression analysis model summary for the independent correlates of female ACS*

\begin{tabular}{|c|c|c|c|c|c|c|c|c|}
\hline Correlates & B & S.E. & Wald 2 & df & Odds ratio & \multicolumn{2}{|c|}{ 95\% C.I. } & $p$ \\
\hline Hypertension & 1.630 & 0.660 & 6.093 & 1 & 5.103 & 1.399 & 18.612 & 0.014 \\
\hline Dyslipidemia & 1.327 & 0.672 & 3.892 & 1 & 3.768 & 1.009 & 14.079 & 0.049 \\
\hline HADS-A & 1.462 & 0.735 & 3.962 & 1 & 4.315 & 1.023 & 18.205 & 0.047 \\
\hline DS-14 Type D & 1.527 & 0.761 & 4.027 & 1 & 4.605 & 1.036 & 20.465 & 0.045 \\
\hline Current antidepressant medication & -3.111 & 1.164 & 7.147 & 1 & 0.045 & 0.005 & 0.436 & 0.008 \\
\hline
\end{tabular}

* Backward Likelihood Ratio procedure; ACS cases coded as 1. HADS-A: Hospital Anxiety and Depression Scale - Anxiety; HADS-D: Hospital Anxiety and Depression Scale Depression; ACS: Acute coronary syndrome 
HADS - A

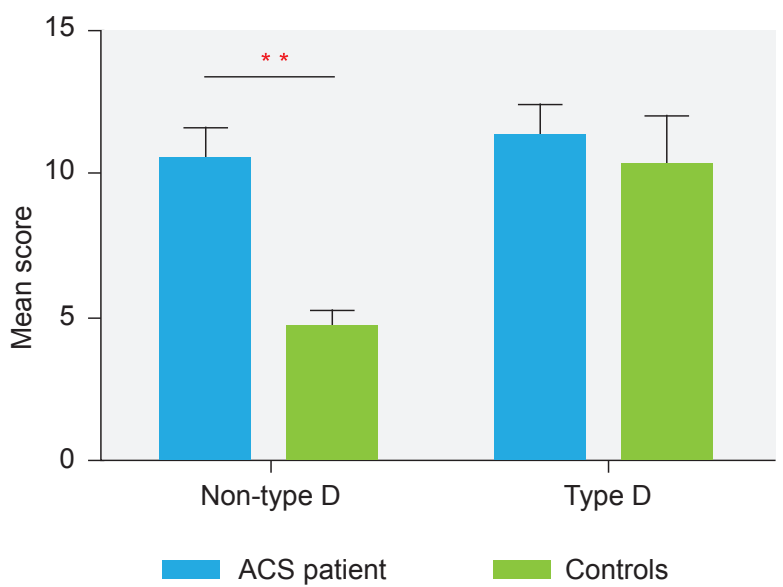

HADS - D

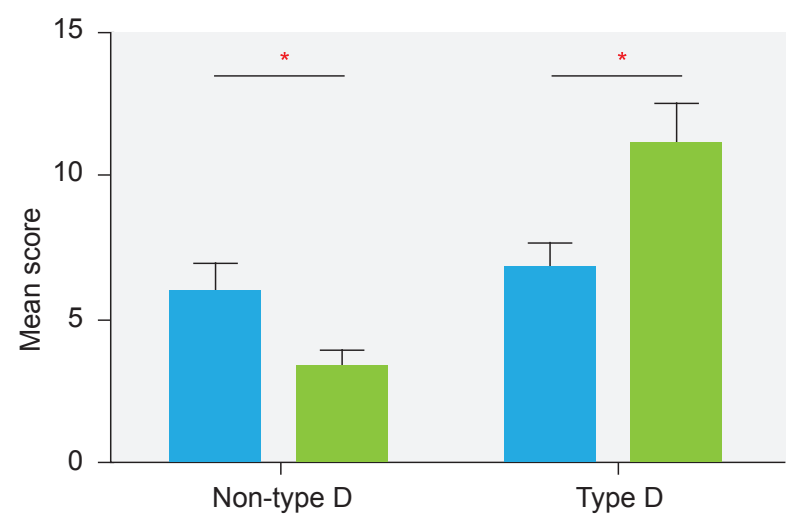

Figure 1 - Mean HADS-A and HADS-D scores stratified by personality status (non-type D vs type D) and group (control vs ACS patients) HADS-A: Hospital Anxiety and Depression Scale - Anxiety; HADS-D: Hospital Anxiety and Depression Scale - Depression; ACS: Acute coronary syndrome. Paired comparisons revealed that among the non-type-D participants, ACS patients displayed significantly more symptoms of anxiety $(t=-4.49 ; p<0.001)$ and depression $(t=-2.24 ; p<0.05)$ than controls. Interestingly, this effect inverted for type-D participants and HADS-D scores $(t=3.10 ; p<0.05)$. Error bars were plotted using the standard error of the mean (SE). ${ }^{\star} p<0.05,{ }^{*} p<0.001$.

non-type-D (M = 9.67; SE = 0.98) and type-D (M = 11.37; SE $=0.94)$ ACS patients had similar scores $(t=-1.26 ; p=0.22$; n.s.). Correspondingly, a significant main effect of personality status $\left[F(1.73)=20.85 ; p<0.001 ; \eta^{2}=0.22\right]$ was also found on HADS-D scores, with type-D participants $(\mathrm{M}=7.84$; SE $=0.72$ ) reporting significantly more depressive symptoms than non-type-D ( $M=4.00 ; S E=0.52)$. Furthermore, a significant group $\times$ personality status interaction effect on the HADS-D scores was also found $[F(1.73)=11.82 ; p<$ $\left.0.05 ; \eta^{2}=0.14\right]$. Similarly to HADS-A, depressive symptoms were significantly more prevalent in type-D $(M=11.00 ; S E=$ 1.18) than in non-type-D participants $(M=3.24$; $S E=0.61)$ within the control group $(t=-4.88 ; p<0.001)$, whereas no difference was found $(t=-0.97 ; p=0.34$; n.s.) between nontype-D (M = 5.63; SE = 0.87) and type-D (M = 6.72; SE = $0.71)$ ACS patients.

\section{DISCUSSION}

We compared ACS female patients with age-matched female controls on cardiovascular and psychosocial factors to determine whether any psychosocial measure would be independently associated with ACS, and whether type-D personality, a stable personality trait, would be associated with more anxiety and depression symptoms among patients. Not surprisingly, we found higher prevalence of hypertension, diabetes and dyslipidemia among patients compared to controls. We also found a higher prevalence of type-D personality and anxiety symptoms in patients even though no differences were found regarding the prevalence of depressive symptoms. In fact, antidepressant medication was more commonly used by controls. High anxiety scores in patients might reflect an adaptive psychological response to the ACS, which is a major life-threatening event, and not necessarily a true anxiety disorder. In addition, we identified type-D personality as an independent psychosocial predictor of risk for ACS in females. Furthermore, our findings also indicate that type-D personality is associated with more depressive and anxious symptomatology, albeit revealing a distinct expression by group.

Low education generally inflates the prevalence of traditional CVD risk factors such as hypertension and diabetes. ${ }^{32}$ Therefore, we cannot exclude the possibility that patients' educational level might have accentuated their prevalence. However, smoking and alcohol consumption habits have also been associated with a low education level, yet no differences were detected for these risk factors. Regarding psychosocial measures, the prevalence of type-D personality was unusually high among patients, whereas controls yielded a prevalence rate which was lower than other community estimates. ${ }^{17,18,21}$ Similarly, the prevalence rate of clinically relevant anxiety symptoms was significantly higher among patients who might reflect an adaptive response to the ACS. However, evidence indicates that anxiety worsens the prognosis of cardiac patients by increasing the risk for recurrent cardiovascular events and thereby the risk of cardiac mortality. ${ }^{13,14}$ Further, anxiety is also an independent risk factor for CVD in community samples, ${ }^{14,15}$ which makes $26 \%$ of control participants a disturbing estimate of clinical anxiety. Unexpectedly, no significant group difference was found in the prevalence rate of depressive symptoms. This null finding may result from a small sample size combined with a high prevalence of depressive symptoms among controls, as suggested by their frequency of antidepressants use. Still, 32\% of patients had clinical symptoms of depression. A similar (31\% - 45\%) rate of patients presenting clinical symptoms following an ACS has been reported elsewhere. ${ }^{33}$ In addition, depression increases the risk for cardiac morbidity and mortality in the general population ${ }^{11,12}$ which makes the estimate of clinical symptoms among female controls also a concern. Nonetheless, antidepressants use and psychiatric referrals were significantly less common among patients. This finding may reflect the general assumption that depression remains largely under-recognized and under-treated in 
cardiac patients, although safe and effective antidepressant treatments are available..$^{33}$

In this study, several independent predictors of ACS were identified. Among the traditional CVD risk factors assessed, dyslipidemia and hypertension increased the likelihood for an ACS in a 3- and 5-fold risk, respectively. Such independent contributions to ACS risk are well documented in longitudinal studies..$^{34,35}$ We also found that the presence of type $D$ personality and less frequent antidepressant use were all independent predictors of ACS. Whereas the latter may reflect a systematic influence in this particular population (i.e., reluctance by clinicians in prescribing antidepressants), the 4-fold increase in risk for ACS associated with type-D personality is worth highlighting. Although beyond the scope of this study, putative mechanisms mediated by anxiety symptoms and/ or distressed personality may implicate a combination of heightened autonomic reactivity, changes in platelet function, and endothelial dysfunction subsequent to periods of stress exposure. ${ }^{7,36}$ Nevertheless, the identification of clinical predictors can help outline a high risk profile which may guide prevention strategies in women and lead to an optimization of resources. Accordingly, type-D personality coupled with hypertension and dyslipidemia, delineated such a profile.

Contrary to what is commonly believed, ${ }^{37,38}$ type-D personality was not associated with increased anxiety and depression symptoms among patients. This finding is particularly striking given that type-D personality is usually associated with higher levels of stress, mental distress, and increased physical symptoms in cardiac patients. ${ }^{39}$ However, type-D personality was indeed associated with increased anxiety and depression symptoms among the controls. This interesting finding can have several interpretations. First, the fact that both patients and controls scoring positive for type-D personality were indistinct regarding anxiety symptoms suggests that type-D personality could have acted as a 'buffer' through a mechanism of stress cognitive appraisal ${ }^{40}$ following the cardiac event (i.e., acute stressor). Second, type-D personality patients had significantly less depressive symptoms than their control counterparts. It could be hypothesized that type-D personality participants resort to negative affectivity as an emotional coping strategy, which becomes less responsive once a life-threatening event occurs. In fact, other studies have also found that negative affectivity was unrelated to depressive symptoms following an AMI, ${ }^{41}$ and that depression was unrelated to CVD severity in type-D patients. ${ }^{42}$ In other words, our data overall suggest that type-D works as a risk factor for cardiac events by amplifying the expression of negative affect, and that this influence becomes diminished once the disease is established.

Our study has some limitations that we acknowledge. First, our sample size hinders generalization of findings and could have limited power to unmask hidden effects (see above). Second, although type-D personality was associated with both anxiety and depressive symptoms differently by group, this study employed a cross-sectional design thus making the valuation of type- $D$ personality influences over time speculative, at best. However, to our knowledge, this study is pioneer in examining these associations with a female-specific focus. Women are still under-represented in clinical cardiovascular research although evidence of clear-cut gender differences in biomedical and psychosocial risk factors and medical outcomes urges further research in women.

The evaluation of psychosocial risk factors in women with CVD would contribute to better risk stratification and help the clinician to provide adequate intervention if required. Studies examining the benefits of psychological interventions in cardiac patients have shown varying results, some pointing out no clear benefits whilst others have reported significant reductions in mortality. ${ }^{43}$ The Stockholm's Women's Intervention Trial for Coronary Artery Disease (SWITCHD) indicated that psychossocial interventions could produce an almost 3-fold higher protective effect on mortality compared to standard medical care. ${ }^{44}$ Those interventions aimed to control behavioral risk factors, attenuate negative emotions, improve coping skills, reduce stress, and improve social support. ${ }^{44}$ It is generally accepted that psychosocial interventions in patients with CVD illness should focus on the training and practice of social and coping skills so that patients can better handle stressful situations and experience less negative affect. ${ }^{45}$ However, to our knowledge, no studies have evaluated the cardiovascular impact of those interventions among female type-D personality patients.

\section{CONCLUSIONS}

Our findings indicate that female ACS patients reveal a disproportionate prevalence of type-D personality, fact that merits clinical attention since type $D$ personality is known to facilitate additive effects of hypertension and dyslipidemia in terms of worse cardiac prognosis. However, in this study, the levels of anxiety and depression reported by patients following an acute cardiac event were apparently unrelated to type-D personality, a pattern that clearly contrasted with that of controls. Future research should examine how psychosocial factors cluster in women and which putative mechanisms allow them to interact with acute cardiovascular events. Moreover, it is priceless to determine whether interventions aimed at type-D personality are beneficial in terms of mortality decrease and quality of life improvements. Ultimately, this will translate into more effective femalespecific prevention strategies and better patient outcomes.

\section{ACKNOWLEDGMENTS}

The corresponding author was supported by a Portuguese Government Fellowship (Fundação para a Ciência e a Tecnologia, SFRH/BD/70327/2010), as part of her $\mathrm{PhD}$ thesis in the University of Porto. 


\section{PROTECTION OF HUMANS AND ANIMALS}

The authors declare that the procedures were followed according to the regulations established by the Clinical Research and Ethics Committee and to the Helsinki Declaration of the World Medical Association.

\section{DATA CONFIDENTIALITY}

The authors declare having followed the protocols in use at their working center regarding patients' data publication.

\section{CONFLICTS OF INTEREST}

All authors report no conflict of interest.

\section{FUNDING SOURCES}

The corresponding author was supported by a Portuguese Government Fellowship (Fundação para a Ciência e a Tecnologia, SFRH/BD/70327/2010, as part of her $\mathrm{PhD}$ thesis in the University of Porto). For the remaining authors no competing interests were disclosed.

\section{REFERENCES}

1. Möller-Leimkühler AM. Gender differences in cardiovascular disease and comorbid depression. Dialogues Clin Neurosci. 2007;9:71-83.

2. Vaccarino V, Badimon L, Corti R, de Wit C, Dorobantu M, Hall A, et al. Ischaemic heart disease in women: Are there sex differences in pathophysiology and risk factors? Position paper from the working group on coronary pathophysiology and microcirculation of the european society of cardiology. Cardiovas Res. 2011;90:9-17.

3. Gulati M, Shaw LJ, Bairey Merz CN. Myocardial ischemia in women: Lessons from the nhlbi wise study. Clin Cardiol. 2012;35:141-8.

4. Maas AHEM, van der Schouw YT, Regitz-Zagrosek V, Swahn E, Appelman YE, Pasterkamp G, et al. Red alert for women's heart: The urgent need for more research and knowledge on cardiovascular disease in women: Proceedings of the workshop held in brussels on gender differences in cardiovascular disease, 29 september 2010. Eur Heart J. 2011;32:1362-8.

5. Edwards ML. The enigma of heart disease in women: New insights may precipitate diagnosis and improve patient outcomes. J Am Acad Nurse Pract. 2012;24:574-8.

6. Prata J, Ramos S, Martins AQ, Rocha-Gonçalves F, Coelho R. Women with coronary artery disease: Do psychosocial factors contribute to a higher cardiovascular risk? Cardiol Rev. 2014;22:25-9.

7. Rozanski A, Blumenthal JA, Davidson KW, Saab PG, Kubzansky L. The epidemiology, pathophysiology and management of psychosocial risk factors in cardiac practice - the emerging field of behavioral cardiology. J Am Coll Cardiol. 2005;45:637-51.

8. Lespérance F. Five-year risk of cardiac mortality in relation to initial severity and one-year changes in depression symptoms after myocardial infarction. Circulation. 2002;105:1049-53.

9. Frasure-Smith N, Lespérance F. Reflections on depression as a cardiac risk factor. Psychosom Med. 2005;67:19-25.

10. Rosengren A, Hawken S, Ounpuu S, Sliwa K, Zubaid M, Almahmeed $\mathrm{Wa}$, et al. Association of psychosocial risk factors with risk of acute myocardial infarction in 11119 cases and 13648 controls from 52 countries (the interheart study): Case-control study. Lancet. 2004;364:953-62.

11. Gustad LT, Laugsand LE, Janszky I, Dalen H, Bjerkeset O. Symptoms of anxiety and depression and risk of acute myocardial infarction: The hunt 2 study. Eur Heart J. 2014;35:1394-403.

12. Seldenrijk A, Vogelzangs N, Batelaan NM, Wieman I, van Schaik DJF, Penninx BJ. Depression, anxiety and 6-year risk of cardiovascular disease. J Psychosom Res. 2015;78:123-9.

13. Frasure-Smith N, Lespérance F. Depression and anxiety as predictors of 2-year cardiac events in patients with stable coronary artery disease. Arch Gen Psychiatr. 2008;65:62-71.

14. Roest AM, Martens EJ, de Jonge P, Denollet J. Anxiety and risk of incident coronary heart disease: A meta-analysis. J Am Coll Cardiol. 2010;56:38-46.

15. Janszky I, Ahnve S, Lundberg I, Hemmingsson T. Early-onset depression, anxiety, and risk of subsequent coronary heart disease: 37-year follow-up of 49,321 young swedish men. J Am Coll Cardiol. 2010;56:31-7.

16. Rafanelli C, Roncuzzi R, Ottolini F, Rigatelli M. Psychological factors affecting cardiologic conditions. Adv Psychosom Med. 2007;28:72-108.

17. Denollet J. Ds14: standard assessment of negative affectivity, social inhibition, and type d personality. Psychosom Med. 2005;67:89-97.

18. Hausteiner C, Klupsch D, Emeny R, Baumert J, Ladwig KH. Clustering of negative affectivity and social inhibition in the community: Prevalence of type d personality as a cardiovascular risk marker. Psychosom Med. 2010;72:163-71.

19. Mols F, Denollet J. Type d personality in the general population: A systematic review of health status, mechanisms of disease, and work-

related problems. Health Qual Life Outcomes. 2010;8:9.

20. Grande G, Romppel M, Glaesmer H, Petrowski K, Herrmann-Lingen C. The type-d scale (ds14) - norms and prevalence of type-d personality in a population-based representative sample in germany. Pers Individ Dif. 2010;48:935-9.

21. Wiltink J, Beutel ME, Till Y, Ojeda FM, Wild PS, Münzel T, et al. Prevalence of distress, comorbid conditions and well being in the general population. J Affect Disord. 2011;130:429-37.

22. Denollet J, Pedersen SS, Vrints CJ, Conraads VM. Usefulness of type d personality in predicting five-year cardiac events above and beyond concurrent symptoms of stress in patients with coronary heart disease. Am J Cardiol. 2006;97:970-3.

23. Martens EJ, Mols F, Burg MM, Denollet J. Type d personality predicts clinical events after myocardial infarction, above and beyond disease severity and depression. J Clin Psychiatr. 2010;71:778-83.

24. Thygesen K, Alpert JS, Jaffe AS, Simoons ML, Chaitman BR, White $\mathrm{HD}$, et al. Third universal definition of myocardial infarction. Circulation. 2012;126:2020-35.

25. Folstein M, Folstein S, McHush P. Mini-mental state. A practical method for grading the cognitive state of patients for the clinician. J Psychiatr Res. 1975;12:189-98.

26. Bjelland I, Dahl AA, Haug TT, Neckelmann D. The validity of the hospital anxiety and depression scale. J Psychosom Res. 2002;52:69-77.

27. Zigmond AS, Snaith RP. The hospital anxiety and depression scale. Acta Psychiatr Scand. 1983;67:361-70.

28. Pais-Ribeiro J, Silva I, Ferreira T, Martins A, Meneses R, Baltar M. Validation study of a portuguese version of the hospital anxiety and depression scale. Psychol Health Med. 2007;12:225-35.

29. Doyle F, McGee HM, De La Harpe D, Shelley E, Conroy R. The hospital anxiety and depression scale depression subscale, but not the beck depression inventory-fast scale, identifies patients with acute coronary syndrome at elevated risk of 1-year mortality. J Psychosom Res. 2006;60:461-7.

30. Rocha A. Escala de personalidade tipo d. Validação para a população portuguesa. Lisboa: Universidade Lusófona; 2015.

31. Emons WH, Meijer RR, Denollet J. Negative affectivity and social inhibition in cardiovascular disease: Evaluating type-d personality and its assessment using item response theory. J Psychosom Res. 2007;63:27-39.

32. Panagiotakos DB, Pitsavos CE, Chrysohoou Ca, Skoumas J, Toutouza $\mathrm{M}$, Belegrinos $\mathrm{D}$, et al. The association between educational status and risk factors related to cardiovascular disease in healthy individuals: The attica study. Ann Epidemiol. 2004;14:188-94.

33. Celano CM, Huffman JC. Depression and cardiac disease a review. Cardiol Rev. 2011;19:130-42.

34. Lewington S, Whitlock G, Clarke R, Sherliker P, Emberson J, Halsey J, et al. Blood cholesterol and vascular mortality by age, sex, and blood pressure: A meta-analysis of individual data from 61 prospective studies with 55000 vascular deaths. Lancet. 2007;370:1829-39.

35. Lewington S, Clarke R, Qizilbash N, Peto R, Collins R, Prospective Studies Collaboration. Age-specific relevance of usual blood pressure to vascular mortality: A meta-analysis of individual data for one million adults in 61 prospective studies. Lancet. 2002;360:1903-13.

36. von Känel R. Psychosocial stress and cardiovascular risk: current opinion. Swiss Med Wkly. 2012;142:w13502.

37. Starrenburg AH, Kraaier K, Pedersen SS, van Hout M, Scholten M, van der Palen J. Association of psychiatric history and type d personality with symptoms of anxiety, depression, and health status prior to icd implantation. Int J Behav Med. 2013;20:425-33.

38. Kupper N, Pedersen SS, Höfer S, Saner H, Oldridge N, Denollet 
J. Cross-cultural analysis of type d ( distressed ) personality in 6222 patients with ischemic heart disease : A study from the international heartqol project. Int J Cardiol. 2013;166:327-33

39. Denollet J, Schiffer AA, Spek V. A general propensity to psychological distress affects cardiovascular outcomes: Evidence from research on the type d (distressed) personality profile. Circ Cardiovasc Qual Outcomes. 2010;3:546-57.

40. Lazarus SR. Progress on a cognitive-motivational-relational theory of emotion. Am Psychol. 1991;46:819-34.

41. Marchesi C, Ossola P, Scagnelli F, Paglia F, Aprile S, Monici A, et al. Type $d$ personality in never-depressed patients and the development of major and minor depression after acute coronary syndrome. J Affect Disord. 2014;155:194-9.
42. Denollet J, Jonge PD, Kuyper A, Schene AH, Melle JP, Ormel J, et al. Depression and type d personality represent different forms of distress in the myocardial infarction and depression - intervention trial. Psychol Med. 2009:749-56.

43. Rees K, Bennett P, West R, Davey S, Ebrahim S. Psychological interventions for coronary heart disease. Cochrane Database Syst Rev. 2004;2:CD002902.

44. Orth-Gomér K, Schneiderman N, Wang HX, Walldin C, Blom M, Jernberg T. Stress reduction prolongs life in women with coronary disease: The stockholm women's intervention trial for coronary heart disease (switchd). Circ Cardiovasc Qual Outcomes. 2009;2:25-32

45. von Känel R. Psychosocial stress and cardiovascular risk: current opinion. Swiss Med Wkly. 2012;142:w13502. 